\title{
Lentiviral expression system for the purification of secreted proteins from human cell cultures
}

\author{
Alexander Falkenhagen', Sabah Asad ${ }^{2}$, Stanley E. Read ${ }^{2}$ and Sadhna Joshi ${ }^{1,3^{*}}$
}

\begin{abstract}
Background: Recombinant proteins of therapeutic use are ideally produced in human cells to ensure appropriate co- and post-translational modifications. However, purification of secreted proteins from the culture media is impeded by low expression from transfected cell lines and the presence of serum proteins. Here we describe a simple and cost-effective approach based on lentiviral vector-mediated gene delivery and expression of a secreted His-tagged protein from human embryonic kidney 293 T cells and direct affinity chromatography purification from the cell culture media.
\end{abstract}

Results: Using a protein-based HIV entry inhibitor, soluble CD4 (sCD4), we demonstrated that 293 T cells transduced with a lentiviral vector mediated over 10-fold higher secretion of SCD4 in comparison to 293 T cells transfected with the corresponding plasmid. Secretion of SCD4 increased with the dose of the lentiviral vector up to a multiplicity of infection of 50. Exchanging the native signal peptide of SCD4 with the signal peptide of human alpha-1 antitrypsin increased expression by $50 \%$. There was no difference in expression from a monocistronic or bicistronic lentiviral vector. Reduction of the serum concentration in the culture media had no significant effect on the secretion of sCD4. Small-scale purification from $50 \mathrm{ml}$ of culture media with reduced serum content yielded up to $1 \mathrm{mg}$ of pure sCD4. Purified sCD4 bound to recombinant HIV envelope glycoprotein 120 (Env gp120) and inhibited HIV entry at concentrations comparable to published results.

Conclusion: The procedure outlined in this study can be performed without the need for specialized reagents or equipment and could easily be adapted by any laboratory. Furthermore, the method could be used to produce sCD4 fusion proteins or other His-tagged proteins.

Keywords: His-tag, Human cells, Lentiviral vector, Purification, Secreted proteins, Soluble CD4

Abbreviations: AAT, Alpha-1 antitrypsin; BSA, Bovine serum albumin; CATNAP, Compile, Analyze and Tally NAb Panels; CHO, Chinese hamster ovary; CMV, Cytomegalovirus; ELISA, Enzyme-linked immunosorbent assay; Env gp120, Envelop glycoprotein 120; FBS, Fetal bovine serum; Fc, Crystalizing fragment; HEK, Human embryonic kidney; IC50s, Half maximal inhibitory concentrations; IgG, Immunoglobulin G kappa chain; MOI, Multiplicity of infection; PEI, Polyethylenimine; sCD4, Soluble CD4; TCID50, 50 \% tissue culture infectious dose; TPA, Tissue plasminogen activator; WPRE, Woodchuck hepatitis post-transcriptional regulatory element; a-Gal, Galactose-a-1,3-galactose

\footnotetext{
* Correspondence: sadhna.joshi.sukhwal@utoronto.ca

${ }^{1}$ Department of Laboratory Medicine \& Pathobiology, University of Toronto,

Toronto, Canada

${ }^{3}$ Department of Molecular Genetics, University of Toronto, Toronto, Canada

Full list of author information is available at the end of the article
} 


\section{Background}

Expression systems based on bacteria, yeast, insect cells and plants have successfully been used to express recombinant proteins at high levels. Each system has its own advantages, but none can fully recapitulate the extensive co- and post-translational modifications found in some human proteins [1-4]. In order to ensure functionality and to be as close as possible to their native state, many human proteins are now produced in Chinese hamster ovary $(\mathrm{CHO})$ cells and human embryonic kidney (HEK) cells. Both cell lines are well established and have been utilized to produce clinically relevant proteins [5]. While both $\mathrm{CHO}$ and HEK cells are capable of extensive glycosylations, it has recently become more and more evident that proteins produced in $\mathrm{CHO}$ cells have a different glycosylation pattern than the same proteins produced in HEK cells, which may affect their function [6-10]. For example, a fusion protein containing the extracellular domain of the human interleukin-23 receptor and a crystalizing fragment $(\mathrm{Fc})$ region produced in HEK cells was less stable in mice than the same protein produced in $\mathrm{CHO}$ cells [6]. In another study, an Fc receptor (CD16) produced in HEK cells exhibited slower antibody binding and dissociation kinetics in comparison to CD16 from CHO cells [7]. While the exact implications of differences in glycosylation are not yet fully understood, a strong argument for the production of therapeutic proteins in HEK cells is made by the finding that $\mathrm{CHO}$ cells can add terminal galactose- $\alpha-1,3$-galactose ( $\alpha$-Gal) to proteins $[11,12] . \alpha-G a l$ is a non-human antigenic glycan and its reaction with circulating antibodies present in most individuals can lead to anaphylaxis $[11,13]$. This glycan is absent in proteins produced in HEK cells [14].

Production of secreted proteins in human cells is usually achieved by large-scale transient transfections to compensate for low expression levels. However, repeated large-scale transfections require high quantities of a transfection reagents and plasmid DNAs. Highly efficient transfection systems with specialized reagents and cell lines are available, but are commonly substituted with polyethylenimine (PEI) transfection of HEK cells to reduce the cost [15-17]. An alternative to transient transfection is the generation of stable clonal cell lines [18]. Stable chromosomal integration and expression from transfected DNA relies on coupling protein expression to a selectable marker. Since transgene expression varies depending on the integration site, different clones are isolated by limiting dilution and tested for transgene expression, which is tedious. Transduction with lentiviral vectors is another method of generating stable cell lines. Cells transduced with lentiviral vectors have been used to express secreted proteins $[19,20]$. However, the lentiviral vector backbones used in these studies were custom made and are not readily available. Furthermore, production and titration of these vectors required specific cell lines, media, and lengthy concentration procedures $[19,20]$. Regardless of the expression system, the recombinant proteins are usually purified from $\geq 11$ cell culture supernatants. Since standard culture media contain high amounts of serum proteins that can interfere with the purification process or contaminate the final protein preparations [21], serum proteins are removed prior to protein purification or specialized serum-free media is used.

In order to facilitate the purification process, the protein of interest is usually fused to a protein tag (e.g. human influenza hemagglutinin). Immobilized antibodies directed against the protein tag are commonly used to isolate the protein of interest from the culture media [15].

Here we describe a simple and effective method for the purification of a His-tagged human protein from the culture media of lentiviral vector-transduced HEK 293 T cells. All reagents are readily available at a relatively low cost and no specialized equipment is needed to complete the procedure. Using soluble CD4 (sCD4), a truncated version of the CD4 receptor that is secreted, we were able to purify up to $1 \mathrm{mg}$ of the protein from small-scale cell cultures. The expression system and the purification method used here can easily be adapted for purification of other proteins by most laboratories.

\section{Methods}

\section{Cells, plasmids and proteins}

HEK 293 T cells were obtained from Dr. Jason Moffat (University of Toronto, Toronto, Canada). $293 \mathrm{~T}$ and TZM-bl cells were cultured in Dulbecco's modified Eagle's medium (DMEM; Thermo Fisher Scientific, Waltham, United States) supplemented with $10 \%$ fetal bovine serum (FBS, Thermo Fisher Scientific) and $1 \%$ Antibiotic-Antimycotic (Thermo Fisher Scientific). The self-inactivating bicistronic lentiviral vector pLV-CMV was constructed by replacing the PstI-to-NheI fragment of pLVX-IRES-ZsGreen1 (Clontech, Mountain View California, United States) with the compatible NsiI-toAvrII fragment from pLJM1-EGFP [22]. The monocistronic vector $\mathrm{pLV}-\mathrm{CMV}-\mathrm{M}$ was generated by deleting the SacII fragment of pLV-CMV. The gene encoding sCD4 (amino acids 1-209 of CD4, UniProtKB P01730, followed by GGGSGAGCCPGCC HHHHHH) and the different signal peptides were synthesized and sequenced by Genscript (Piscataway, United States). The gene encoding sCD4 was preceded by an EcoRI site and followed by a NotI site and cloned as an EcoRI-to-NotI fragment into the multiple cloning site of the bicistronic lentiviral vector $\mathrm{pLV}-\mathrm{CMV}$ to generate $\mathrm{pLV}-\mathrm{CMV}-\mathrm{sCD} 4$. The nucleotide sequence of the signal peptides was flanked by an EcoRI site at the 5' end and nucleotides 76-218 of the open reading frame of $\mathrm{sCD} 4$ containing an ApaI site at the 3 ' end. The EcoRI-to-ApaI fragments containing the 
different signal peptide sequences were each used in tripartite ligation reactions with the ApaI-to-BamHI and $B a m$ HI-to-EcoRI fragments of pLV-CMV-sCD4 to generate pLV-CMV-AAT-sCD4, pLV-CMV-TPA-sCD4 and pLV-CMV-IgG-sCD4. The AAT-sCD4 gene was transferred from pLV-CMV-AAT-sCD4 as an NdeI-to-NotI fragment to the corresponding sites of the monocistronic vector $\mathrm{pLV}-\mathrm{CMV}-\mathrm{M}$ to generate $\mathrm{pLV}-\mathrm{CMV}-\mathrm{M}-\mathrm{AAT}-\mathrm{sCD}$. The pJRFL-env and pHXB2-env plasmids expressing HIV Env gp160 from HIV $\mathrm{IRFL}_{\text {In }}$ and $\mathrm{HIV}_{\mathrm{HXB2}}$, respectively, were a kind gift from Dr. Donald Branch (University of Toronto). The following reagents were obtained through the NIH AIDS Reagent Program, Division of AIDS, NIAID, NIH: psPAX2 and pMD2.G from Dr. Didier Trono; TZM-bl and $\mathrm{pSG}^{\Delta \text { env }}$ from Drs. John C. Kappes and Xiaoyun Wu [23-28]; sCD4-183 from Pharmacia Inc. [29]; and HIV $\mathrm{BaL}_{\mathrm{L}}$ gp120.

\section{Production and titration of lentiviral vector particles} On day one, $7 \times 10^{6} 293 \mathrm{~T}$ cells were seeded into a $10 \mathrm{~cm}$ cell culture dish in $9 \mathrm{ml}$ culture media. $24 \mathrm{~h}$ later, the media were replaced with $9 \mathrm{ml}$ fresh media. $1.5 \mathrm{~h}$ later, chloroquine (Bioshop, Burlington, Canada) was added at a final concentration of $25 \mu \mathrm{M} .10 .5 \mu \mathrm{g}$ of the lentiviral vector construct, $7 \mu \mathrm{g}$ of psPAX2 and $3.5 \mu \mathrm{g}$ of pMD2.G were added to a $1.5 \mathrm{ml}$ tube in a final volume of $450 \mu \mathrm{l} .50 \mu \mathrm{l}$ of $2.5 \mathrm{M}$ calcium chloride were added dropwise and the tube was vortexed for a short time. After $5 \mathrm{~min}, 500 \mu \mathrm{l}$ of $2 \mathrm{xHBS}$ ( $50 \mathrm{mM}$ HEPES, $1.5 \mathrm{mM}$ disodium hydrogen phosphate, $280 \mathrm{mM}$ sodium chloride, $10 \mathrm{mM}$ potassium chloride, and $12 \mathrm{mM}$ sucrose) were added dropwise to form calcium phosphate-DNA precipitate. After vortexing the tube for a short period, the mixture was incubated for $1 \mathrm{~min}$ and added dropwise to the cells. The next day, media were exchanged with $10 \mathrm{ml}$ fresh media and the cells were incubated for $48 \mathrm{~h}$. Culture supernatants were harvested, filtered $\left(0.45 \mu \mathrm{m}\right.$ pore size), aliquotted and stored at $-80{ }^{\circ} \mathrm{C}$. To determine the titer, $2 \times 10^{5} 293 \mathrm{~T}$ cells were mixed with serial dilutions of the vector particles in the presence of polybrene (final concentration $8 \mu \mathrm{g} / \mathrm{ml}$; Sigma Aldrich, Missouri, Unites States) in a 12-well plate in a final volume of $1 \mathrm{ml}$. The percentage of cells that emitted green fluorescence was determined by flow cytometry or fluorescence microscopy after 3 days.

\section{Transfection and transduction of 293 T cells}

For transfection, $7 \times 10^{5} 293 \mathrm{~T}$ cells per well were cultured in $1 \mathrm{ml}$ culture media in a 12-well plate for 1 day. Media were exchanged and $1 \mathrm{~h}$ later each well was transfected with $0.75 \mu \mathrm{g}$ of pLV-CMV-AAT-sCD4 using PolyJet transfection reagent (FroggaBio, North York, Canada) according to the manufacturer's instructions. For transduction, $1 \times 10^{5} 293 \mathrm{~T}$ cells were mixed with the lentiviral vector at the indicated multiplicity of infection (MOI) and polybrene (final concentration $8 \mu \mathrm{g} / \mathrm{ml}$ ) in a 12 -well plate in a $1 \mathrm{ml}$ volume. The cells were incubated for 3-4 days. The cells were sub-cultured for 1-2 weeks and then used in subsequent experiments.

\section{PCR}

Genomic DNA was extracted using the PureLink gDNA mini kit (Thermo Fisher Scientific) according to the manufacturer's instructions. The primer sequences for the detection of integrated vector were A005-F 5'-TCTG TAGCGACCCTTTGCAG-3' and A005-R 5'-CACGCC GTAGAACTTGGACT-3'. The primer sequences for the detection of genomic B-actin were A006-F 5'-CAGC AAGCAGGAGTATGACGA-3' and A006-R 5'- CACTC TGGGTAAG GACAAGTTGG-3'. The primers were synthesized by ACGT DNA Technologies Corporation (Toronto, Canada). PCRs were set up using 2X Taq FroggaMix (Froggabio), $0.5 \mu \mathrm{g}$ genomic DNA, and $1.5 \mu \mathrm{M}$ forward and reverse primers. The cycles were: 1 ) $94{ }^{\circ} \mathrm{C}$ for $10 \mathrm{~min}$; 2) $94{ }^{\circ} \mathrm{C}$ for $0.5 \mathrm{~min}$; 3) $60{ }^{\circ} \mathrm{C}$ for $0.5 \mathrm{~min}$; 4) $72{ }^{\circ} \mathrm{C}$ for $0.5 \mathrm{~min}$; and 5) $72{ }^{\circ} \mathrm{C}$ for $10 \mathrm{~min}$. Cycles 2-4 were repeated 24 times.

\section{Detection and purification of His-tagged proteins}

Culture media were clarified by short centrifugation at low speed. His-tagged proteins in the culture media were detected using a competitive Enzyme-linked immunosorbent assay (ELISA; Genscript) according to the manufacturer's instructions. Briefly, culture media and a mouse anti-His-tag mAb were added to wells coated with a His-tagged protein. The wells were washed and bound $\mathrm{mAb}$ was detected with an horseradish peroxidase (HRP)-conjugated goat anti-mouse IgG. Following additional washes, HRP activity was visualized using 3,3',5,5' -tetramethylbenzidine substrate and the reaction was stopped. SDS-PAGE, Coomassie blue staining, and Western blot analyses were performed as described previously [30, 31]. Some gels were stained using One-Step Blue Protein Gel Stain (Biotium, Hayward, United States). For purification, a HisTalon cobalt gravity column (Clontech) was equilibrated with $10 \mathrm{ml}$ equilibration buffer $(50 \mathrm{mM}$ sodium phosphate, $300 \mathrm{mM}$ sodium chloride; $\mathrm{pH}$ 7.4). $50 \mathrm{ml}$ of the clarified culture media were directly applied to the column at room temperature. The column was washed with $8 \mathrm{ml}$ equilibration buffer and $7 \mathrm{ml}$ wash buffer $(50 \mathrm{mM}$ sodium phosphate, $300 \mathrm{mM}$ sodium chloride, $10 \mathrm{mM}$ imidazole; $\mathrm{pH}$ 7.4). The proteins were eluted with $4 \mathrm{ml}$ elution buffer (50 mM sodium phosphate, $300 \mathrm{mM}$ sodium chloride, and $150 \mathrm{mM}$ imidazole; $\mathrm{pH}$ 7.4) in 3 fractions (first fraction, $1 \mathrm{ml}$; second fraction $1.5 \mathrm{ml}$; and third fraction $1.5 \mathrm{ml})$. The second fraction contained the majority of the protein and was applied to a $5 \mathrm{ml}$ Zeba spin column 
with $7 \mathrm{~K}$ MWCO (Thermo Fisher Scientific) to exchange the elution buffer with PBS.

\section{HIV gp120 binding assay}

Purified HIV $\mathrm{BaL}_{\mathrm{Ba}}$ gp120 $(2 \mu \mathrm{g} / \mathrm{ml} ; 100 \mu \mathrm{l}$ per well $)$ was diluted in $0.05 \mathrm{M}$ sodium carbonate buffer, $\mathrm{pH} 9.6$ and coated onto untreated 96-wells overnight at $4{ }^{\circ} \mathrm{C}$. Uncoated wells served as a control. Wells were washed 4 times with PBS containing $0.05 \%$ Tween 20 (Sigma), blocked with PBS containing $5 \%$ bovine serum albumin fraction V (BSA, Bioshop) for $2 \mathrm{~h}$ at room temperature, followed by 4 washes. $50 \mu \mathrm{l}$ of sCD4 diluted in PBS containing $0.1 \%$ BSA and $0.05 \%$ Tween 20 were added to all wells at the indicated concentrations and incubated overnight at $4{ }^{\circ} \mathrm{C}$. Wells were washed 4 times and incubated with $50 \mu \mathrm{l}$ of a ready-to-use mouse anti-His-tag monoclonal antibody solution (Genscript) for $1 \mathrm{~h}$ at room temperature. After 4 additional washes, $100 \mu \mathrm{l}$ of a ready-to-use HRP-conjugated goat anti-mouse IgG solution (Genscript) were added to each well and the plates were incubated for $30 \mathrm{~min}$. After 4 washes, $100 \mu \mathrm{l}$ of 3,3',5,5'-Tetramethylbenzidine substrate (Genscript) were added for $5 \mathrm{~min}$ and the reaction was stopped by adding Stop Solution (Genscript). The OD at $450 \mathrm{~nm}$ was determined using a standard plate reader and background values obtained for control wells were subtracted.

\section{Antiviral assay}

Replication-incompetent virus was generated by transfecting $293 \mathrm{~T}$ cells with $10.5 \mu \mathrm{g}$ of pSG3 ${ }^{\Delta \text { env }}$ encoding the HIV genome with a deletion in the HIV Env gp160 open reading frame and $10.5 \mu \mathrm{g}$ of an HIV Env gp160encoding plasmid (pHXB2-env, pJRFL-env or pMD2.G) using the calcium phosphate transfection method described above for lentiviral vector particle production. The $50 \%$ tissue culture infectious dose (TCID50) and inhibition of HIV entry were determined in TZM-bl cells, which express the lac $Z$ gene under the control of the HIV long terminal repeat promoter. Virus $\left(5 \times 10^{3}\right.$ TCID50) was mixed with sCD4 at the indicated concentration and added to $5 \times 10^{4} \mathrm{TZM}$-bl cells together with polybrene $(8 \mu \mathrm{g} / \mathrm{ml}$ final concentration) in 24-well plates. The cells were incubated for 2 days, fixed with $1 \%$ formaldehyde for $5 \mathrm{~min}$, and stained with X-Gal $(0.4 \mathrm{mM}$ potassium ferricyanide, $0.4 \mathrm{mM}$ potassium ferrocyanide, $20 \mathrm{mM}$ magnesium chloride, $0.4 \mu \mathrm{g} / \mathrm{ml} \mathrm{X}$-Gal) overnight at room temperature. Three random microscope images were taken for each well and infected (blue) cells were counted.

\section{Statistical analysis}

Data are presented as means $+/$ - standard error of the mean. Where appropriate, unpaired $t$ test was used to test for statistical difference between two groups.

\section{Results and discussion}

\section{Lentiviral vector expressing SCD4 and transduction of} HEK 293 T cells

sCD4 mimics the natural CD4 receptor that is necessary for HIV entry into target cells. The secreted protein is the first HIV entry inhibitor described in the literature [32]. Administration of high doses of $\mathrm{sCD} 4$ produced in $\mathrm{CHO}$ cells has been shown to reduce viral load in two small clinical trials [33, 34]. However, frequent injections of highly purified proteins were not feasible for the longterm treatment of HIV-infected individuals. Currently, sCD4 is used in countless studies examining the mechanism and inhibition of HIV entry. The open reading frame of the $s C D 4$ gene used in this study is comprised of the native signal peptide and the first two domains of CD4, which allow binding to the HIV Env gp120. The second domain is followed by a $6 x$ His-tag. A schematic of sCD4 is shown in Fig. 1a. While the His-tag may be less effective than newer tags, it is one of the most widely used tags and antibodies as well as resins for affinity chromatography are available at a relatively low cost.

We chose to express sCD4 in HEK 293 T cells because of their human origin and availability in many laboratories. We used a self-inactivating lentiviral vector, LVCMV-sCD4, to minimize activation of neighboring genes [35]. The vector contained the human cytomegalovirus immediate early (CMV) promoter and is highly active in $293 \mathrm{~T}$ cells [36]. The bicistronic mRNA transcribed from this vector allows simultaneous expression of sCD4 and the enhanced fluorescent reporter protein ZsGreen1 [37]. Additionally, the vector contained the woodchuck hepatitis post-transcriptional regulatory element (WPRE), which has been shown to increase both the titer and transgene expression in conjunction with the CMV promoter [38, 39]. Similar vectors are readily available at any plasmid repository. A schematic of the vector is shown in Fig. 1a.

Calcium phosphate transfection of $293 \mathrm{~T}$ cells resulted in sufficiently high vector titers without the need for further concentration of vector particles. $293 \mathrm{~T}$ cells showed a vector dose-dependent increase in the expression of ZsGreen1. Both the percentage of transduced cells and fluorescence intensity increased with higher doses as shown by fluorescence microscopy and flow cytometry (Fig. 1b and c, respectively). Simultaneously, the concentration of sCD4 in the culture supernatant of transduced $293 \mathrm{~T}$ cells increased with the vector dose (Fig. 1d).

\section{Utilizing heterologous signal peptides to increase secretion}

The signal peptide is responsible for directing proteins to the secretory pathway. Altering the signal peptide 


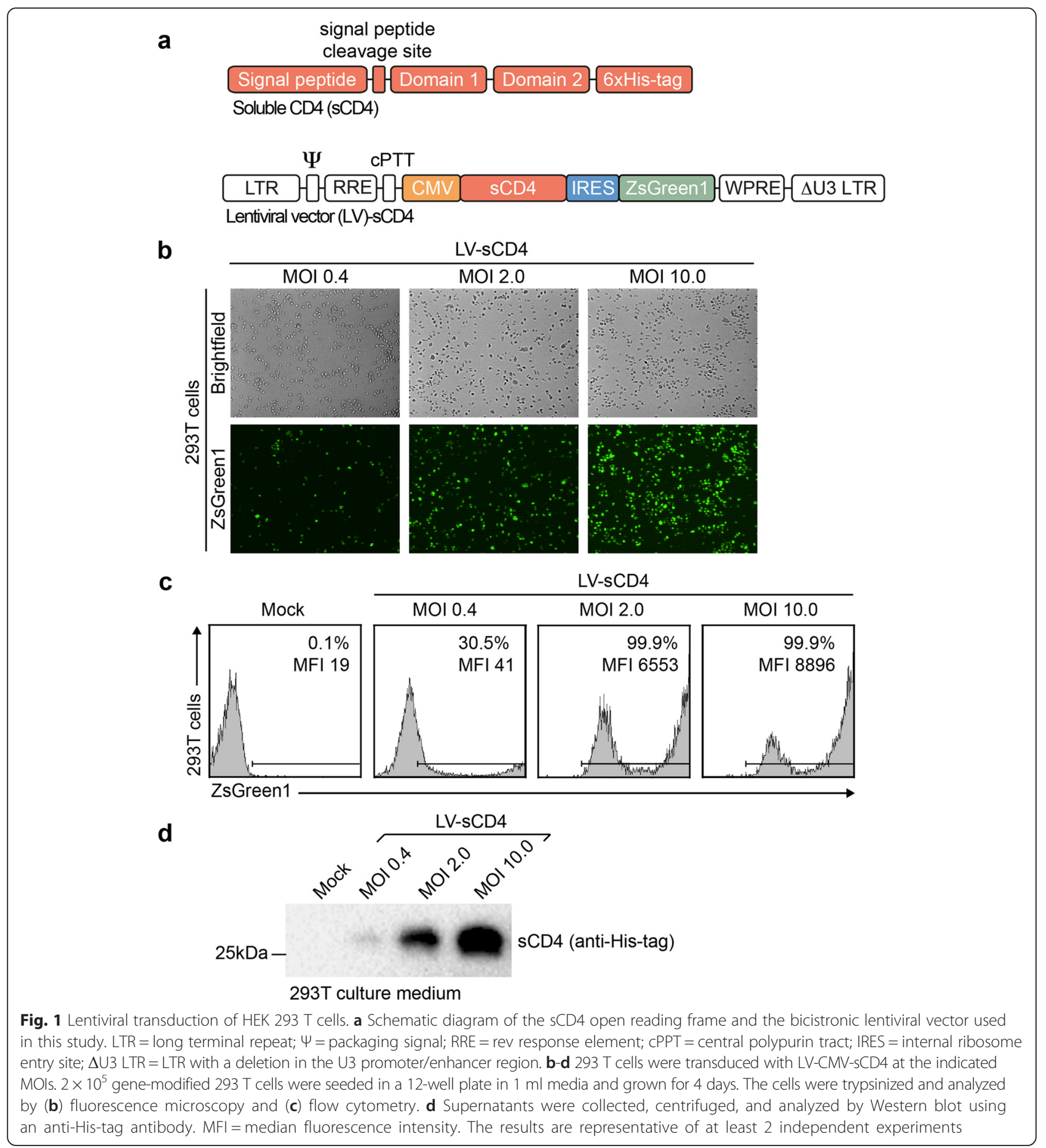

sequence has previously been shown to increase secretion for some proteins $[40,41]$. We exchanged the natural signal peptide of sCD4 with three commonly used signal peptides and analyzed the resulting amino acid sequences with the bioinformatics program SignalP, which discriminates secreted from non-secreted proteins [42]. The signal peptides and their SignalP scores are depicted in Fig. 2a. The highest score was obtained for sCD4 with the alpha-1 antitrypsin (AAT) signal peptide. The score for sCD4 with the immunoglobulin G kappa chain signal peptide (IgG) was same as the score for $\mathrm{SCD} 4$ with the native signal peptide. $\mathrm{sCD} 4$ with the signal peptide of the tissue plasminogen activator (TPA) yielded the lowest score. The $s C D 4$ genes with the different signal peptides were cloned into the lentiviral vector and the resulting vectors were used to transduce $293 \mathrm{~T}$ cells. The percentage of gene-modified cells was $>90 \%$ for all vectors at a MOI of 2 (data not shown). The AAT signal 

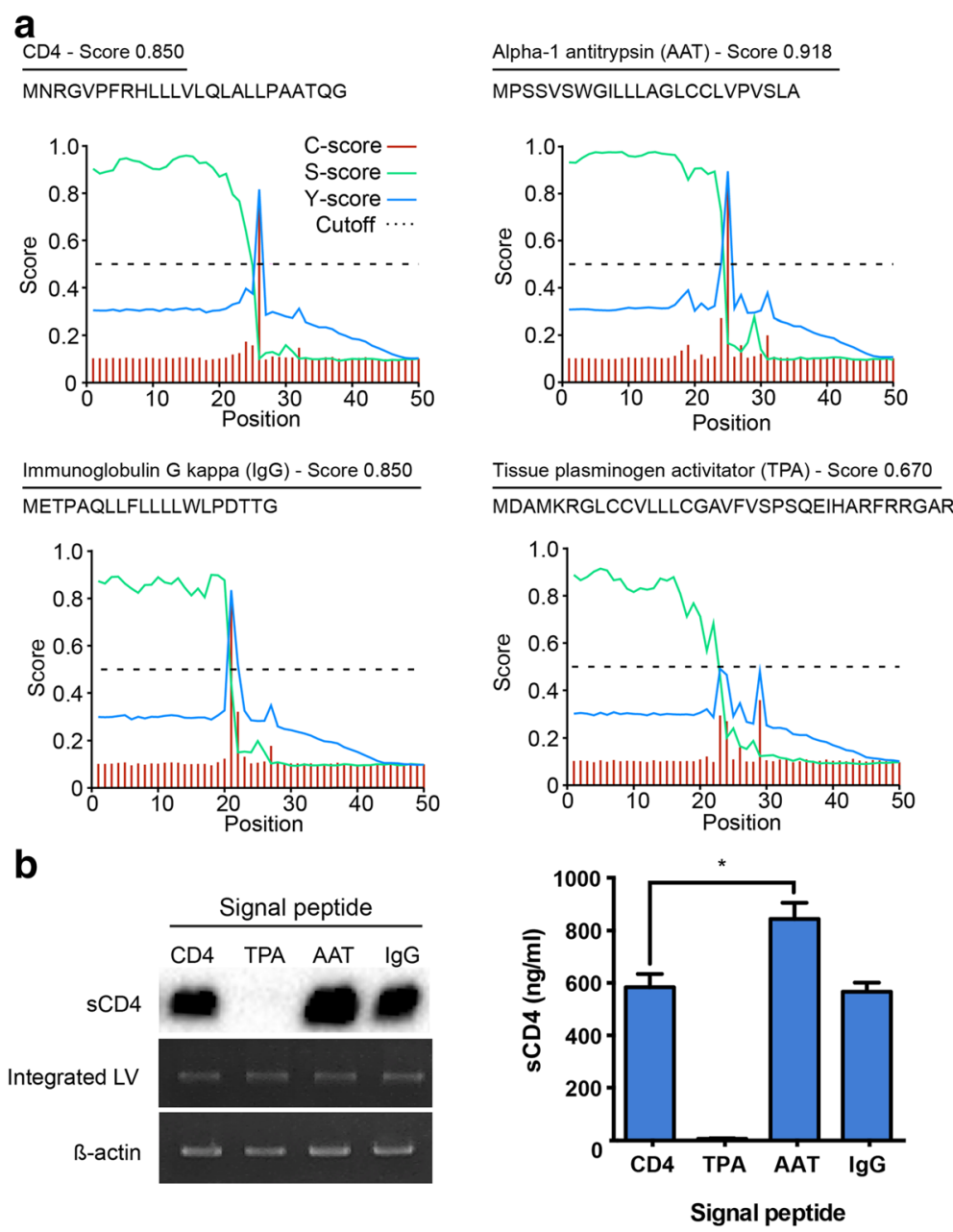

Fig. 2 Utilizing alternative signal peptides to optimize protein secretion. a The signal peptide prediction software SignalP was used to analyze sCD4 with different signal peptide sequences. The C-score identifies the signal peptide cleavage site. The S-score distinguishes signal peptides from the mature protein. The Y-score is a combination of the C- and S-scores. The signal peptides, their sequence, and their final score are indicated. b 293 T cells were transduced with LV-CMV-sCD4 (CD4), LV-CMV-TPA-sCD4 (TPA), LV-CMV-AAT-sCD4 or LV-CMV-IgG-sCD4 (IgG) encoding sCD4 with the indicated signal peptide at a MOI of $2.2 \times 10^{5}$ gene-modified 293 T cells were seeded in a 12-well plate in $1 \mathrm{ml}$ media and cultured for 4 days. Genomic DNA was extracted from the cells and examined for the presence of integrated vector by PCR with vector-specific primers. PCR with $\beta$-actin primers was performed as a control for equal input DNA (left panel). Supernatants were collected, centrifuged, and analyzed by Western blot using an anti-His-tag antibody (left panel) and His-tag ELISA (right panel). The results are representative of 2 independent experiments performed in duplicates; ${ }^{*} p<0.05$

peptide mediated a $50 \%$ increase in protein concentration, while the TPA signal peptide caused a decrease, and the IgG signal peptide no significant change (Fig. 2b). Semi-quantitative PCR analysis of genomic DNA from these cells indicated that the observed differences in sCD4 secretion levels were not due to varying copy numbers of the integrated proviral vector DNA (Fig. 2b). The protein concentration in the culture media seemed to correlate with the predicted Signal P scores, e.g. the sCD4 with the AAT signal peptides had the highest score and was present at the highest concentration. Since the AAT signal peptide mediated a significant increase over the native CD4 signal peptide, all subsequent experiments were performed with sCD4 containing the AAT signal peptide.

\section{HEK 293 T cells can be transduced at high MOls}

$293 \mathrm{~T}$ cells are an easy to transduce cell line and close to $100 \%$ transduction efficiency can be achieved at relatively low MOIs. In order to determine the maximal vector dose that can be used, $293 \mathrm{~T}$ cells were transduced with LV-CMV-AAT-sCD4 at MOIs ranging from 0.4 to 100. Although reduced cell viability was evident immediately after transduction at a MOI of 100 , all cells recovered after a week (data not shown). The SCD4 concentration in the media increased up to a MOI of 50 (Fig. 3a). No 

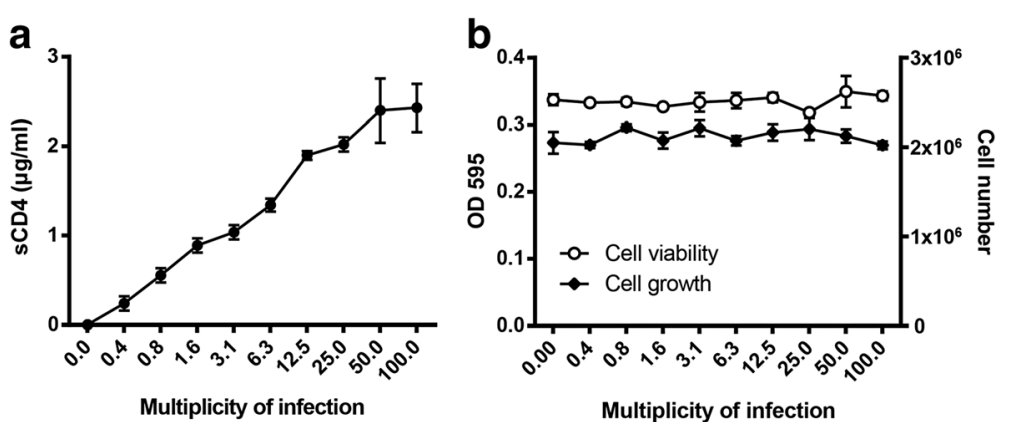

Fig. 3 Human 293 T cells can be transduced at high MOls. 293 T cells were transduced with LV-CMV-AAT-sCD4 at the indicated MOls. $2 \times 10^{5}$ gene-modified 293 T cells were seeded in a 12-well plate in $1 \mathrm{ml}$ media and cultured for 4 days. a Concentration of sCD4 in the culture supernatants determined by His-tag ELISA. b Cell growth analyzed by microscopy and cell viability determined by MTT-assay. The results are representative of at least 2 independent experiments

differences in cell growth or viability were evident in comparison to untransduced control cells (Fig. 3b). Therefore, cells transduced at a MOI of 50 were used in the following experiments.

\section{Optimizing conditions for the purification of sCD4}

Lentiviral vector design can significantly affect transgene expression. For example, clear differences between monocistronic and bicistronic lentiviral vectors have been shown to exist between different cell types [43]. We generated a monocistronic vector, LV-CMV-M, by removing the ZsGreen1 open reading frame from pLVCMV. The titer of the monocistronic vector encoding sCD4 with the AAT signal peptide, LV-CMV-M-AATsCD4, was determined using HIV p24 antigen ELISA because it did not encode ZsGreen1. $293 \mathrm{~T}$ cells were transduced at a 24 concentration equaling a $\mathrm{MOI}$ of 50 for the bicistronic vector encoding $\mathrm{SCD} 4$ with the $\mathrm{AAT}$ signal peptide, LV-CMV-AAT-sCD4. When sCD4 expression from cells transduced with the mono- or bicistronic vector was compared in parallel, no significant difference in protein concentration in the culture media was detected (Fig. 4a). This result showed that the bicistronic vector design did not have a negative effect on the expression of sCD4 under the tested conditions. Consequently, a bicistronic vector was used in the following experiments. However, if larger transgenes are used, a monocistronic vector may be used because the titer of lentiviral vectors can drop with the increased vector size.

Transient expression is commonly used to produce secreted proteins in mammalian cells. Using a commercially available transfection reagent, we compared sCD4 expression from $293 \mathrm{~T}$ cells transfected with the plasmid pLV-CMV-AAT-sCD4 to sCD4 expression from $293 \mathrm{~T}$ cells transduced with the lentiviral vector LV-CMVAAT-sCD4. Transfected and transduced $293 \mathrm{~T}$ cells were cultured under the same conditions. Importantly, the
SCD4 concentration in the culture supernatants from transduced $293 \mathrm{~T}$ cells was over 10-fold higher than in the supernatants from transfected $293 \mathrm{~T}$ cells (Fig. 4b). This result indicated that expression of secreted proteins from transduced cells was advantageous not only in terms of convenience, but also protein yield.

Standard culture media contain high quantities of serum proteins, which are undesirable for the purification of recombinant proteins. In our experience, $293 \mathrm{~T}$ cells can tolerate low levels of serum once they reach a confluent monolayer. To examine if reducing the serum concentration in standard media affects the concentration of secreted protein, transduced cells were grown to confluence and fresh media with a 10-fold reduced serum concentration were added. Figure $4 \mathrm{c}$ shows that reducing the serum concentration did not negatively affect sCD4 secretion. Accordingly, simply using standard culture media with reduced serum presents a costeffective approach to reduce potential contaminants.

In an experiment to evaluate the effect of incubation time, cells were grown to confluence and reduced serum media were added. Culture supernatants were collected after 1-5 days of culture and then analyzed for the sCD4 concentration by ELISA and SDS-PAGE. ELISA results showed that the SCD4 concentration was the highest after 5 days of incubation (Fig. 4, left panel). However, Coomassie blue staining of an SDS-PAG showed the appearance of additional bands after 3 days, including a band corresponding to a slightly higher molecular weight protein than $\mathrm{sCD} 4$ (Fig. 4, right panel), which could represent $\mathrm{sCD} 4$ with an uncleaved signal peptide and indicate cell leakage of cellular proteins into the culture media. Therefore, 2 days of incubation after the media change were considered optimal for sCD4 production. Nevertheless, the incubation time could be increased, if the secreted protein is stable and a higher yield is desired, albeit potentially at the cost of purity. 


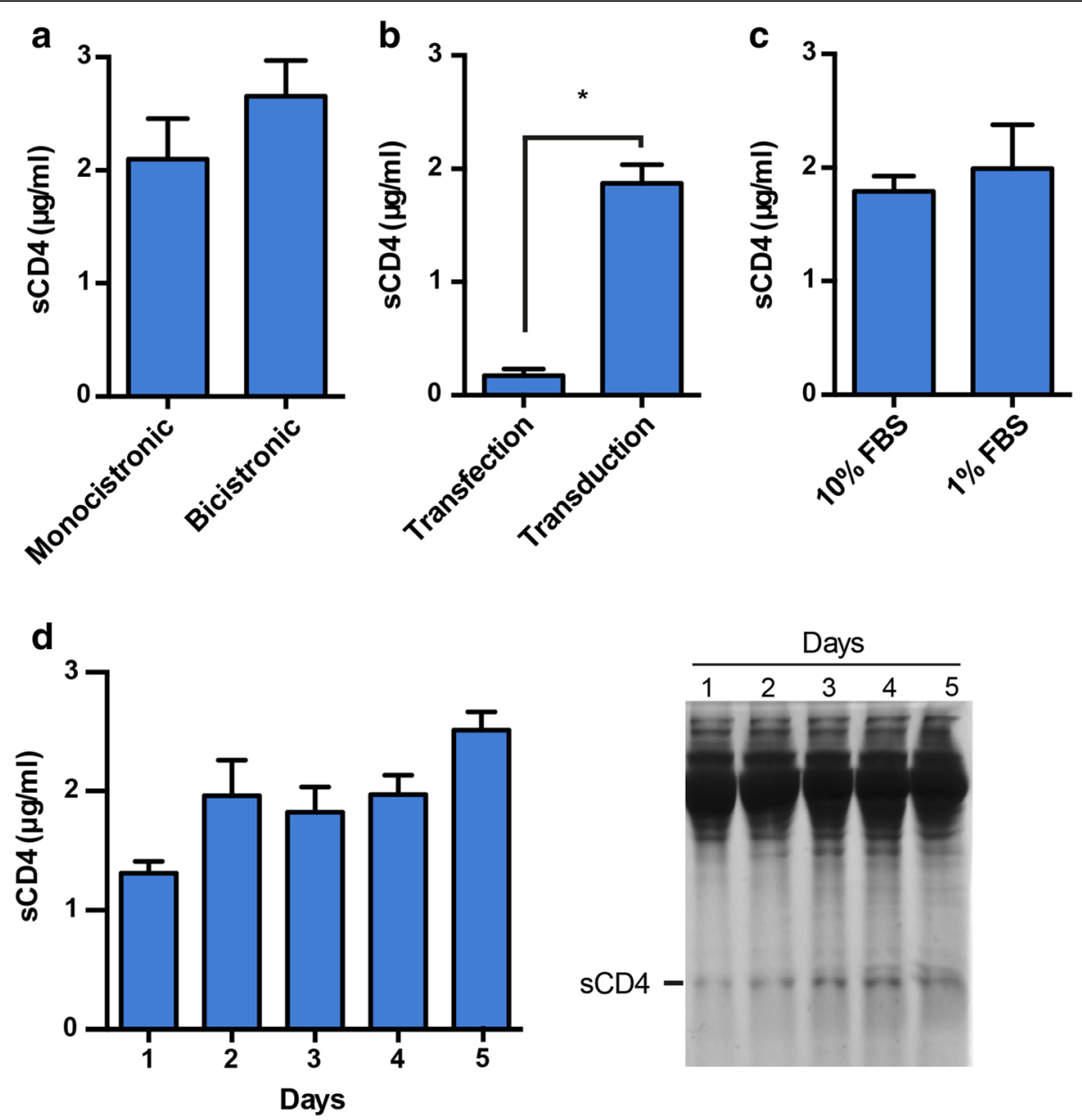

Fig. 4 Optimizing conditions for the purification of sCD4. a Monocistronic versus bicistronic vector design. Cells were transduced with the bicistronic vector LV-CMV-AAT-sCD4 or the monocistronic vector LV-CMV-M-AAT-sCD4 at a MOI of 50. $2 \times 10^{5}$ gene-modified 293 T cells in $1 \mathrm{ml}$ media were plated in a 12-well plate and cultured for 4 days before culture supernatants were analyzed by ELISA. $\mathbf{b}$ Effect of stable versus transient expression on SCD4 secretion levels. $7 \times 10^{5}$ untransduced 293 T cells or 293 T transduced with LV-CMV-AAT-sCD4 were plated in a 12-well plate in $1 \mathrm{ml}$ media and cultured for 1 day. Media were replaced with fresh media and unmodified 293 T cells were transfected with pLV-CMV-AAT-SCD4. On day 2 after plating, media were replaced with fresh media and the cells were cultured for 2 additional days before ELISA was performed on culture supernatants; ${ }^{*} p<0.05$. c Effect of reducing serum concentration. Gene-modified $293 \mathrm{~T}$ cells were cultured and analyzed as in (b), but on day 2 after plating culture media were replaced with media with the indicated FBS concentration. $\mathbf{d}$ Effect of incubation time. Cells were cultured as in (c). Media were replaced on day 2 after plating with media containing $1 \%$ FBS and supernatants were analyzed at the indicated time points by ELISA (left panel) or SDS-PAGE followed by Coomassie blue staining (right panel). All results are representative of 2 independent experiments performed in duplicates

\section{Purification of sCD4}

For affinity chromatography purification of the protein, cells were grown in five $10 \mathrm{~cm}$ cell culture dishes. Culture supernatants $(50 \mathrm{ml})$ from transduced cells grown in reduced serum media were clarified by centrifugation and directly applied to a cobalt column. His-tagged protein was eluted and desalted. The purified protein was analyzed by SDS-PAGE, followed by Coomassie blue staining. The final product contained $\mathrm{sCD} 4$ devoid of any major contaminating bands (Fig. 5a). The concentration of purified sCD4 was $48 \mu \mathrm{g} / \mathrm{ml}$, as determined by ELISA. However, in preliminary HIV entry inhibition assays, the antiviral activity of purified $\mathrm{sCD} 4$ was over 10-fold higher than expected based on previously published results (data not shown). Consequently, we compared our purified sCD4 to an sCD4 protein standard with a known concentration. SDS-PAGE analysis showed that the actual concentration was closer to $800 \mu \mathrm{g} / \mathrm{ml}$, about 16.5-fold higher than the ELISA result suggested (Fig. 5b). Therefore, care should be taken if ELISA is used to determine the protein concentration.

\section{Purified SCD4 specifically inhibits HIV entry}

The functionality of sCD4 was assessed in an HIV Env gp120-binding assay and by inhibition of HIV entry (Fig. 6). sCD4 bound to immobilized gp120 in a dose- 


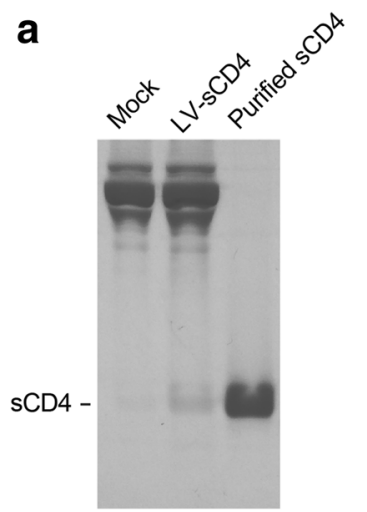

\section{b}

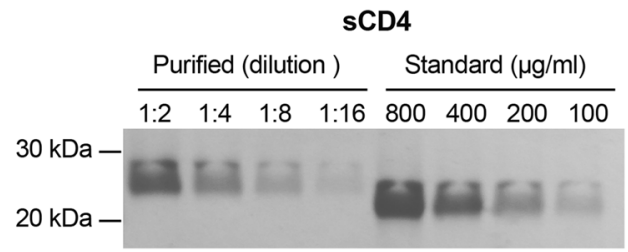

Fig. 5 Affinity purification of sCD4. a SDS-PAGE analysis of purified SCD4. $7 \times 10^{6}$ gene-modified 293 T cells were seeded into five $10 \mathrm{~cm}$ dishes. Media were exchanged to fresh media 1 day after plating. On the second day, media were replaced with $10 \mathrm{ml}$ fresh media containing $1 \%$ FBS and the cells were incubated for 2 additional days before sCD4 was purified from the supernatants. Samples from unmodified cells (mock), gene-modified cells (LV-sCD4) and purified sCD4 were analyzed by SDS-PAGE followed by Coomassie blue staining. b Comparison of purified sCD4 to an sCD4 standard from the National Institutes of Health. Equal volumes of the standard and purified sCD4 were analyzed by SDS-PAGE followed by Coomassie blue staining. Results are representative of 3 independent experiments
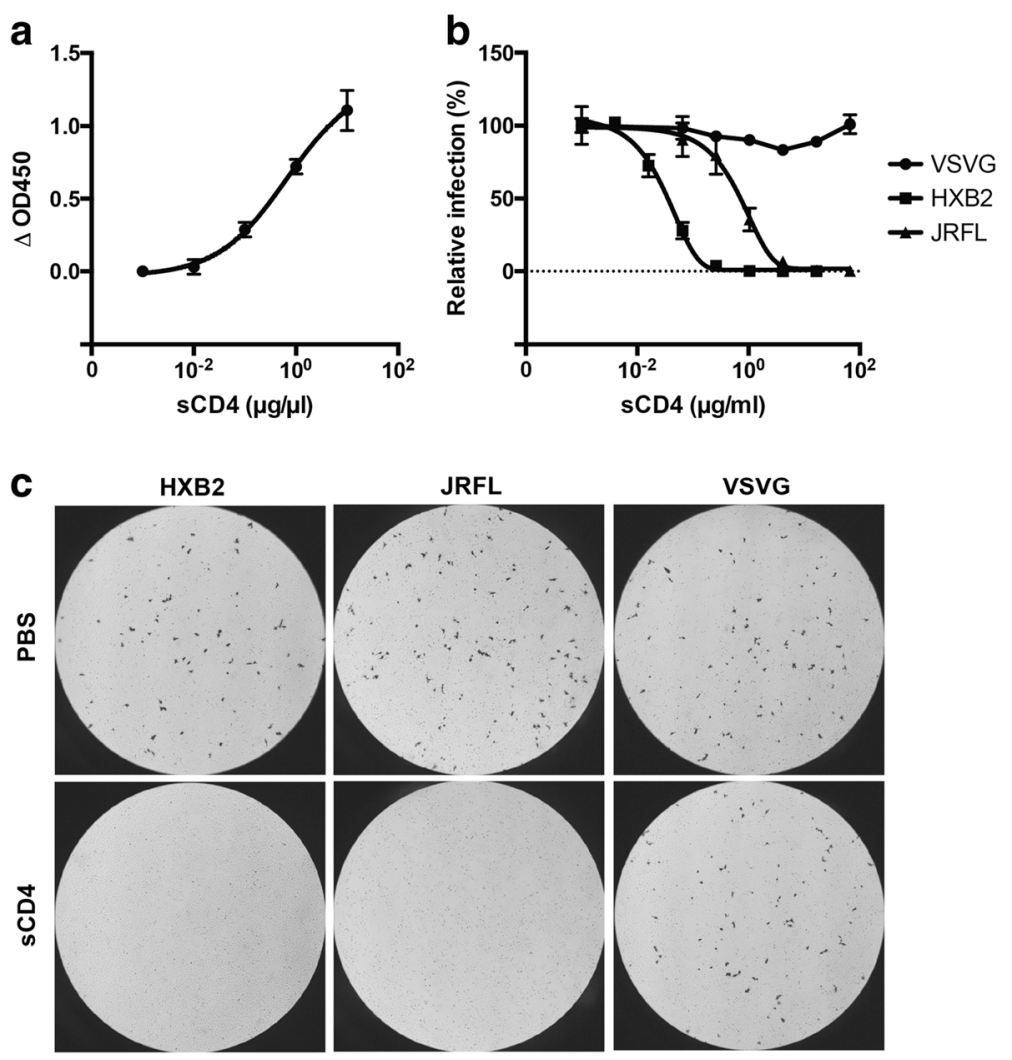

Fig. 6 Antiviral effect of purified SCD4. a Binding of SCD4 to gp120. b Inhibition of HIV entry. $5 \times 10^{4}$ TZM-bl cells were infected with replicationincompetent virus pseudotyped with the indicated HIV Env $\left(\mathrm{TCID} 50\right.$ of $\left.5 \times 10^{3}\right)$ in the presence of the indicated concentration of sCD4. On day 2 post-infection, $\beta$-galactosidase activity was determined by incubation with X-gal. For each sample, the number of infected cells was determined by counting the blue cells from 3 random microscopy images. c Representative microscopy images of cells infected in the presence $(16 \mu \mathrm{g} / \mathrm{ml})$ or absence of sCD4. The results are representative of 2 independent experiments 
Table 1 Protein concentration and IC50s

\begin{tabular}{|c|c|c|c|c|c|c|c|c|}
\hline \multirow[t]{2}{*}{ Method } & \multicolumn{4}{|c|}{ Protein concentration $(\mu \mathrm{g} / \mathrm{ml})$} & \multicolumn{2}{|c|}{ IC50 ( $\mu \mathrm{g} / \mathrm{ml})$} & \multicolumn{2}{|c|}{ CATNAP IC50 $(\mu \mathrm{g} / \mathrm{ml})$} \\
\hline & Purification 1 & Purification 2 & Purification 3 & Mean \pm SEM & $\overline{\mathrm{HXB2}}$ & $\overline{J R F L}$ & HXB2 & JRFL \\
\hline ELISA & 48 & 82 & 69 & $66 \pm 10$ & 0.002 & 0.042 & 0.023 & 1.520 \\
\hline Adjusted & 800 & 1353 & 1133 & $1095 \pm 160$ & 0.032 & 0.684 & & \\
\hline
\end{tabular}

dependent manner (Fig. 6a). Entry of HIV strains was examined in a single-round infection assay. Replicationincompetent HIV particles were pseudotyped with the HIV $_{\text {HXB2 }}$ or HIV JRFL Env gps or the unrelated VSV-G. Both HIV strains need CD4 as the primary receptor, but HIV $_{\text {HXB2 }}$ utilizes CXCR4 as a co-receptor and HIV JRFL uses CCR5 as a co-receptor. In contrast, VSV-G requires the low-density lipoprotein receptor for entry. The pseudoviruses were mixed with SCD4 and added to the CD4 ${ }^{+} \mathrm{CXCR}_{4}{ }^{+} \mathrm{CCR} 5{ }^{+} \mathrm{TZM}$-bl cells, which express the lacZ gene under control of the HIV Tat protein. On day 2 post-infection, cells were stained with a ß-galactosidase substrate (X-Gal) to visualize infected cells. Infection by both of the HIV strains was inhibited in a dosedependent manner, while VSV-G entry remained unaffected (Fig. 5b). Consistent with the literature, HIV $_{\text {HXB2 }}$ was more sensitive to inhibition by sCD4 than HIV $_{\text {JRFL }}$ (Fig. $6 \mathrm{~b}$ and Table 1). Figure $6 \mathrm{c}$ shows representative microscopy images of infected wells. The half maximal inhibitory concentrations (IC50s) obtained in our experiments were comparable to previously published results (Table 1), confirming that concentrations obtained by ELISA underestimated the actual protein concentration.

The sCD4 concentrations of purified preparations as determined by ELISA and the adjusted concentrations in relation to an SCD4 standard are shown. The corresponding IC50s are compared to IC50s from the Los Alamos HIV Database (CATNAP, Compile, Analyze and Tally NAb Panels; http://hiv.lanl.gov/catnap).

\section{Conclusions}

We have developed an efficient and easy-to-follow method to produce high quantities of sCD4 from human cells. $293 \mathrm{~T}$ cells can be transduced with lentiviral vectors at high MOIs. The transduced $293 \mathrm{~T}$ cells can be grown into a confluent monolayer and then be cultured in media with reduced serum concentration, which is a cost-effective solution to minimize serum protein contaminations in the purified protein preparations. Depending on the stability of the secreted protein, the cells can be incubated for several days before culture supernatants are harvested. Using cost-effective metal ion affinity chromatography, we have demonstrated that pure preparations of His-tagged protein can be obtained in a one-step process. We have further shown that using an alternative signal peptide could increase the protein yield. Screening potential signal peptides with the freely available software SignalP may be helpful to identify promising test candidates, but the best signal peptides would have to be experimentally determined for different proteins. The procedure should easily be adaptable for purifying other secreted proteins. For example, we have used this method to successfully produce the single chain antibody $17 \mathrm{~b}$ in similar quantities as well as SCD4 fusion proteins, albeit at 3-fold lower concentrations. This strategy can be adapted to a large-scale format without significantly increasing the cost to further improve the yield.

\section{Acknowledgements \\ This study was supported by Operating Grants from Canadian Institutes of Health Research and Canadian Foundation for AIDS Research.}

\section{Availability of data and materials}

The data set supporting the results of this article are included within the article.

\section{Authors' contributions}

AF, MA, and SA performed the experiments. AF and SJ designed the experiments, interpreted the results and wrote the manuscript. SR participated in the design of the study and helped draft the manuscript. All authors read and approved the final manuscript.

\section{Competing interests}

The authors declare that they have no competing interests.

\section{Author details}

${ }^{1}$ Department of Laboratory Medicine \& Pathobiology, University of Toronto, Toronto, Canada. ${ }^{2}$ Department of Pediatrics, The Hospital for Sick Children, Toronto, Canada. ${ }^{3}$ Department of Molecular Genetics, University of Toronto, Toronto, Canada.

Received: 28 June 2016 Accepted: 29 July 2016

Published online: 02 September 2016

\section{References}

1. Rosano GL, Ceccarelli EA. Recombinant protein expression in Escherichia coli: advances and challenges. Front Microbiol. 2014;5:172.

2. Mattanovich D, Branduardi P, Dato L, Gasser B, Sauer M, Porro D. Recombinant protein production in yeasts. Methods Mol Biol. 2012;824:329-58.

3. van Oers MM, Pijlman GP, Vlak JM. Thirty years of baculovirus-insect cell protein expression: from dark horse to mainstream technology. J Gen Virol. 2015;96(Pt 1):6-23

4. Fahad S, Khan FA, Pandupuspitasari NS, Ahmed MM, Liao YC, Waheed MT, Sameeullah M, Darkhshan, Hussain S, Saud S et al. Recent developments in therapeutic protein expression technologies in plants. Biotechnol lett. 2015, 37(2):265-279.

5. Swiech K, Picanco-Castro V, Covas DT. Human cells: new platform for recombinant therapeutic protein production. Protein Expr Purif. 2012;84(1):147-53.

6. Suen KF, Turner MS, Gao F, Liu B, Althage A, Slavin A, Ou W, Zuo E, Eckart M, Ogawa T, et al. Transient expression of an IL-23R extracellular domain FC 
fusion protein in $\mathrm{CHO}$ vs. HEK cells results in improved plasma exposure. Protein Expr Purif. 2010;71(1):96-102.

7. Zeck A, Pohlentz G, Schlothauer T, Peter-Katalinic J, Regula JT. Cell type-specific and site directed N-glycosylation pattern of FcgammaRIlla. J Proteome Res. 2011;10(7):3031-9.

8. Croset A, Delafosse L, Gaudry JP, Arod C, Glez L, Losberger C, Begue D, Krstanovic A, Robert F, Vilbois F, et al. Differences in the glycosylation of recombinant proteins expressed in HEK and $\mathrm{CHO}$ cells. J Biotechnol. 2012;161(3):336-48.

9. Go EP, Liao HX, Alam SM, Hua D, Haynes BF, Desaire H. Characterization of host-cell line specific glycosylation profiles of early transmitted/founder HIV-1 gp120 envelope proteins. J Proteome Res. 2013;12(3):1223-34.

10. Bohm E, Seyfried BK, Dockal M, Graninger M, Hasslacher M, Neurath M, Konetschny C, Matthiessen P, Mitterer A, Scheiflinger F. Differences in $\mathrm{N}$-glycosylation of recombinant human coagulation factor VII derived from BHK, CHO, and HEK293 cells. BMC Biotechnol. 2015;15:87.

11. Bosques CJ, Collins BE, Meador 3rd JW, Sarvaiya H, Murphy JL, Dellorusso G, Bulik DA, Hsu IH, Washburn N, Sipsey SF, et al. Chinese hamster ovary cells can produce galactose-alpha-1,3-galactose antigens on proteins. Nat Biotechnol. 2010;28(11):1153-6.

12. Ashford DA, Alafi CD, Gamble VM, Mackay DJ, Rademacher TW, Williams PJ, Dwek RA, Barclay AN, Davis SJ, Somoza C, et al. Site-specific glycosylation of recombinant rat and human soluble CD4 variants expressed in Chinese hamster ovary cells. J Biol Chem. 1993;268(5):3260-7.

13. Plum M, Michel Y, Wallach K, Raiber T, Blank S, Bantleon Fl, Diethers A, Greunke K, Braren I, Hackl T, et al. Close-up of the immunogenic alpha1,3galactose epitope as defined by a monoclonal chimeric immunoglobulin $\mathrm{E}$ and human serum using saturation transfer difference (STD) NMR. J Biol Chem. 2011;286(50):43103-11.

14. McCue J, Kshirsagar R, Selvitelli K, Lu Q, Zhang M, Mei B, Peters R, Pierce GF, Dumont J, Raso $S$, et al. Manufacturing process used to produce long-acting recombinant factor VIII Fc fusion protein. Biologicals. 2015;43(4):213-9

15. Aydin H, Azimi FC, Cook JD, Lee JE. A convenient and general expression platform for the production of secreted proteins from human cells. J Vis Exp. 2012(65)

16. Baldi L, Muller N, Picasso S, Jacquet R, Girard P, Thanh HP, Derow E, Wurm FM. Transient gene expression in suspension HEK-293 cells: application to large-scale protein production. Biotechnol Prog. 2005;21(1):148-53.

17. Pham PL, Kamen A, Durocher Y. Large-scale transfection of mammalian cells for the fast production of recombinant protein. Mol Biotechnol. 2006;34(2):225-37.

18. Dalton AC, Barton WA. Over-expression of secreted proteins from mammalian cell lines. Protein Sci. 2014;23(5):517-25.

19. Bandaranayake AD, Correnti C, Ryu BY, Brault M, Strong RK, Rawlings DJ. Daedalus: a robust, turnkey platform for rapid production of decigram quantities of active recombinant proteins in human cell lines using novel lentiviral vectors. Nucleic Acids Res. 2011;39(21):e143.

20. Gaillet B, Gilbert R, Broussau S, Pilotte A, Malenfant F, Mullick A, Garnier A, Massie $\mathrm{B}$. High-level recombinant protein production in $\mathrm{CHO}$ cells using lentiviral vectors and the cumate gene-switch. Biotechnol Bioeng. 2010;106(2):203-15.

21. Menge U, Fraune E, Lehmann J, Kula MR. Purification of proteins from cell culture supernatants. Dev Biol Stand. 1987:66:391-401.

22. Sancak Y, Peterson TR, Shaul YD, Lindquist RA, Thoreen CC, Bar-Peled L, Sabatini DM. The Rag GTPases bind raptor and mediate amino acid signaling to mTORC1. Science. 2008;320(5882):1496-501.

23. Platt EJ, Wehrly K, Kuhmann SE, Chesebro B, Kabat D. Effects of CCR5 and CD4 cell surface concentrations on infections by macrophagetropic isolates of human immunodeficiency virus type 1. J Virol. 1998:72(4):2855-64.

24. Derdeyn CA, Decker JM, Sfakianos JN, Wu X, O'Brien WA, Ratner L, Kappes JC, Shaw GM, Hunter E. Sensitivity of human immunodeficiency virus type 1 to the fusion inhibitor T-20 is modulated by coreceptor specificity defined by the V3 loop of gp120. J Virol. 2000;74(18):8358-67.

25. Wei X, Decker JM, Liu H, Zhang Z, Arani RB, Kilby JM, Saag MS, Wu X, Shaw GM, Kappes JC. Emergence of resistant human immunodeficiency virus type 1 in patients receiving fusion inhibitor (T-20) monotherapy. Antimicrob Agents Chemother. 2002:46(6):1896-905.
26. Takeuchi Y, McClure MO, Pizzato M. Identification of gammaretroviruses constitutively released from cell lines used for human immunodeficiency virus research. J Virol. 2008:82(24):12585-8.

27. Platt EJ, Bilska M, Kozak SL, Kabat D, Montefiori DC. Evidence that ecotropic murine leukemia virus contamination in TZM-bl cells does not affect the outcome of neutralizing antibody assays with human immunodeficiency virus type 1. J Virol. 2009;83(16):8289-92.

28. Wei X, Decker JM, Wang S, Hui H, Kappes JC, Wu X, Salazar-Gonzalez JF, Salazar MG, Kilby JM, Saag MS, et al. Antibody neutralization and escape by HIV-1. Nature. 2003;422(6929):307-12.

29. Garlick RL, Kirschner RJ, Eckenrode FM, Tarpley WG, Tomich CS. Escherichia coli expression, purification, and biological activity of a truncated soluble CD4. AIDS Res Hum Retroviruses. 1990;6(4):465-79.

30. Falkenhagen A, Ameli M, Asad S, Read SE, Joshi S. A novel gene therapy strategy using secreted multifunctional anti-HIV proteins to confer protection to gene-modified and unmodified target cells. Gene Ther. 2014;21(2):175-87.

31. Falkenhagen AAM, Asad S, Read SE, Joshi S. Gene therapy using a secreted single chain variable fragment targeting CCR5 to inhibit HIV infection. J Antivir Antiretrovir. 2013;5:085-91.

32. Smith DH, Byrn RA, Marsters SA, Gregory T, Groopman JE, Capon DJ. Blocking of HIV-1 infectivity by a soluble, secreted form of the CD4 antigen. Science. 1987;238(4834):1704-7

33. Schacker T, Coombs RW, Collier AC, Zeh JE, Fox I, Alam J, Nelson K, Eggert $E$, Corey $L$. The effects of high-dose recombinant soluble CD4 on human immunodeficiency virus type 1 viremia. J Infect Dis. 1994;169(1):37-40.

34. Schacker T, Collier AC, Coombs R, Unadkat JD, Fox I, Alam J, Wang JP, Eggert E, Corey L. Phase I study of high-dose, intravenous $\mathrm{rSCD}^{\mathrm{S}}$ in subjects with advanced HIV-1 infection. J Acquir Immune Defic Syndr Hum Retrovirol. 1995;9(2):145-52.

35. Zufferey R, Dull T, Mandel RJ, Bukovsky A, Quiroz D, Naldini L, Trono D. Self-inactivating lentivirus vector for safe and efficient in vivo gene delivery. J Virol. 1998;72(12):9873-80.

36. Qin JY, Zhang L, Clift KL, Hulur I, Xiang AP, Ren BZ, Lahn BT. Systematic comparison of constitutive promoters and the doxycycline-inducible promoter. PLoS One. 2010;5(5):e10611.

37. Gurtu V, Yan G, Zhang G. IRES bicistronic expression vectors for efficient creation of stable mammalian cell lines. Biochem Biophys Res Commun. 1996;229(1):295-8

38. Donello JE, Loeb JE, Hope TJ. Woodchuck hepatitis virus contains a tripartite posttranscriptional regulatory element. J Virol. 1998;72(6):5085-92.

39. Zufferey R, Donello JE, Trono D, Hope TJ. Woodchuck hepatitis virus posttranscriptional regulatory element enhances expression of transgenes delivered by retroviral vectors. J Virol. 1999:73(4):2886-92.

40. Wang JY, Song WT, Li Y, Chen WJ, Yang D, Zhong GC, Zhou HZ, Ren CY, Yu HT, Ling H. Improved expression of secretory and trimeric proteins in mammalian cells via the introduction of a new trimer motif and a mutant of the tPA signal sequence. Appl Microbiol Biotechnol. 2011:91(3):731-40.

41. Wen B, Deng Y, Guan J, Yan W, Wang Y, Tan W, Gao J. Signal peptide replacements enhance expression and secretion of hepatitis $C$ virus envelope glycoproteins. Acta Biochim Biophys Sin (Shanghai). 2011;43(2):96-102.

42. Petersen TN, Brunak S, von Heijne G, Nielsen H. SignalP 4.0: discriminating signal peptides from transmembrane regions. Nat Methods. 2011;8(10):785-6.

43. Dupuy FP, Mouly E, Mesel-Lemoine M, Morel C, Abriol J, Cherai M, Baillou C, Negre D, Cosset FL, Klatzmann D, et al. Lentiviral transduction of human hematopoietic cells by HIV-1- and SIV-based vectors containing a bicistronic cassette driven by various internal promoters. J Gene Med. 2005;7(9):1158-71. 